\title{
Bedside Teaching in Australian Clinical Schools: A National Study
}

\author{
Praveen L. Indraratna, ${ }^{1,2}$ Louise C. Greenup, ${ }^{3}$ and Timothy X. Yang ${ }^{4}$ \\ ${ }^{1}$ University of New South Wales, Sydney, NSW 2052, Australia \\ ${ }^{2}$ St George Hospital, Kogarah, Sydney, NSW 2217, Australia \\ ${ }^{3}$ Nepean Hospital, Sydney, NSW 2747, Australia \\ ${ }^{4}$ Department of Surgery, Monash Medical Centre, Melbourne, VIC 3168, Australia
}

Correspondence should be addressed to Praveen L. Indraratna; praveen@unsw.edu.au

Received 13 August 2013; Revised 20 October 2013; Accepted 20 October 2013

Academic Editor: Saeed Farooq

Copyright (C) 2013 Praveen L. Indraratna et al. This is an open access article distributed under the Creative Commons Attribution License, which permits unrestricted use, distribution, and reproduction in any medium, provided the original work is properly cited.

Purpose. Bedside teaching (BST) of medical students has become less common in recent years; however, there have been strong recommendations made in the literature to continue this teaching modality for the valued benefits it provides. The purpose of the present study is to explore the perceptions and opinions of bedside teaching among senior Australian medical students. Methods. Medical students at Australian universities were surveyed by means of an electronic questionnaire. The results were collected and analysed. Results. A total of 517 responses were received from students at 15 universities and 94 different clinical sites. The percentage of students who identified BST as very important ranged from $62.5 \%$ in psychiatry to $90.4 \%$ in internal medicine. The optimal class size was nominated as 3-4 students, and students favoured a style where one individual performs a complete examination, with the remainder allowed to elicit the key sign afterwards. Students felt 3-4 hours of BST per week to be ideal. Advantages identified to BST included provision of feedback and elicitation of clinical signs. Disadvantages included time constraints and excessive class sizes. Conclusions. The unique benefits of BST result in its high demand by students, regardless of the discipline being taught.

\section{Introduction}

Bedside teaching (BST), defined as when a clinician supervises a group of students at the patient's bedside to elicit a history or physical signs, was once the most common form of medical student teaching [1]. It is currently, however, seen primarily as an adjunctive teaching method to classroombased and informal teaching. Documented reasons for this include time constraints on tutors, increasing reliance on biochemical testing, medical imaging, and consultation of subspecialists [1-3]. Despite this, medical students still desire BST, and anecdotal reports have described declining amounts of this particular teaching modality and, in some centres, a total lack thereof. The opinions and perceptions of current medical students regarding this teaching modality, however, remain largely unpublished.

The present study is the largest survey of students' opinions and perceptions on BST, and it has targeted a multiinstitutional population across the nation. Factors analysed included students' opinions on optimal class size, time devoted to BST, and teaching style, as well as the importance of BST within various medical disciplines.

\section{Methods}

Ethical approval was granted by the University of New South Wales Human Research and Ethics Advisory Panel (ref: AD 11066).

2.1. Literature Search. Initially, the literature was reviewed. Original published studies on BST were identified by searching the Ovid Medline, EMBASE, and PubMed databases from January 1960 to July 2013. To maximise the sensitivity of the search, keywords including "bedside teaching," "students, medical," and "education, medical" were combined and included as keywords or MeSH terms. Non-English-language papers were excluded. The reference lists of all retrieved 
articles were manually reviewed to identify additional potentially relevant studies.

2.2. Questionnaire. After reviewing the literature and identifying necessary areas of research, an anonymous voluntary survey targeting Australian medical students in the final two years of their degree was carried out by means of an electronic questionnaire. This was created using LimeSurvey (http://www.limesurvey.org/en/). The questionnaire was initially piloted on 94 medical students in order to test reliability and validity. The results were discarded, and a revised version of the questionnaire was posted on a freely accessible website and publicised by participating medical societies, either by inclusion in email bulletins or linked from the society website. Confidentiality was protected for all respondents, their universities, and their teaching hospitals. Participants were surveyed on the following three categories:

(1) demographic data,

(2) opinions-students were asked to rate the importance of BST within each discipline using Likert items, as well as providing their opinions on optimal class size, teaching regularity, and style,

(3) free text-students were given the opportunity to comment on advantages, disadvantages, and approaches to BST and space was provided for any additional comments.

2.3. Study Population. Medical students in the final two years of their medical degree at any Australian university were the targeted population of this study.

2.4. Data Extraction and Analysis. Survey results were imported into a Microsoft Excel spreadsheet and subsequently collated and analysed by all three investigators. Incomplete responses were eliminated. Descriptive analysis was performed on the data to provide summative figures, and a narrative review of the tabulated data was performed. Statistical analysis was performed using StatsDirect (version 2.7.8, StatsDirect, Altrincham, UK). Free text responses were examined for common themes and subsequently categorised.

\section{Results}

A total of 578 students were surveyed, with 61 responses excluded as they were incomplete or provided by junior medical students. In total, 517 survey responses were included in this study, comprising students at 15 Australian universities and 94 teaching hospitals. In total, there are 19 medical schools in Australia. 62\% of students who were directly contacted responded to the survey. The total number of senior medical students in Australia is 4,415; thus the survey represents $12 \%$ of the total population [4].

3.1. Demographics. Respondent characteristics can be seen in Table 1. The mean age of respondents was $24.6 \pm 4.0$ years and $64 \%$ were female. Graduate students and international
TABLE 1: Respondent characteristics.

\begin{tabular}{|c|c|}
\hline Variable & $\begin{array}{c}\text { Baseline statistics } \\
(N=517)(\%)\end{array}$ \\
\hline \multicolumn{2}{|l|}{ Sex } \\
\hline Male & $185(36 \%)$ \\
\hline Female & $332(64 \%)$ \\
\hline \multicolumn{2}{|l|}{ Age } \\
\hline Mean age $( \pm S D)$ & $24.62 \pm 4.01$ \\
\hline Median age (interquartile range) & $24(22-25)$ \\
\hline \multicolumn{2}{|l|}{ Domestic/international } \\
\hline Domestic students & $446(86 \%)$ \\
\hline International students & $71(14 \%)$ \\
\hline \multicolumn{2}{|l|}{ Graduate/undergraduate } \\
\hline Graduate students & $199(38 \%)$ \\
\hline Undergraduate students & $318(62 \%)$ \\
\hline \multicolumn{2}{|l|}{ Year level } \\
\hline Third year & $113(22 \%)$ \\
\hline Fourth year & $166(32 \%)$ \\
\hline Fifth year & $106(21 \%)$ \\
\hline Sixth year & $129(25 \%)$ \\
\hline Seventh year & $3(0.005 \%)$ \\
\hline Universities & 15 \\
\hline Hospitals & 94 \\
\hline \multicolumn{2}{|l|}{ Faculty organized BST } \\
\hline Yes & $396(77 \%)$ \\
\hline No & $121(23 \%)$ \\
\hline \multicolumn{2}{|l|}{ Urban/regional } \\
\hline Urban teaching school & $408(79 \%)$ \\
\hline Regional teaching school & $109(21 \%)$ \\
\hline
\end{tabular}

students comprised $38 \%$ and $14 \%$ of the group, respectively, and students from regional teaching hospitals accounted for $21 \%$ of the respondents.

3.2. Student Opinions and Perceptions. In all disciplines, the majority of students noted BST to either be extremely or very important, supporting the notion that despite declining hours, students place a high value upon BST. $90.4 \%$ of respondents felt BST to be "very important" in the study of internal medicine, with corresponding figures of $74.1 \%$ for surgery, $79.7 \%$ for emergency medicine, $62.5 \%$ for psychiatry, $85.1 \%$ for paediatrics, and $74.1 \%$ for obstetrics and gynaecology.

3.2.1. Optimal Class Size and Optimal Number of Hours. A class size of two students was selected as optimal by $19.6 \%$ of respondents, $44.9 \%$ selected three students, and $28.4 \%$ selected four students with the remainder divided between five, six, and seven students. When asked to nominate the optimal number of hours per week of BST, respondents were relatively equally divided (Table 2 ). The mean answer was 4.1 hours. 
TABLE 2: Desired hours of BST per week.

\begin{tabular}{lc}
\hline Hours per week & Percentage of respondents (\%) \\
\hline 0 & 0 \\
1 & 1.6 \\
2 & 15.0 \\
3 & 22.6 \\
4 & 21.2 \\
5 & 14.3 \\
6 & 7.6 \\
7 (or more) & 12.8 \\
\hline
\end{tabular}

3.2.2. Teaching Style. An approach where one student performs a complete physical examination and the remainder of the group elicits the key sign afterward was selected by $49.3 \%$ of respondents. This was more popular than a single student performing a complete examination $(15.4 \%)$ or where the physical examination is divided into sections for students to perform one section each (30.1\%).

3.3. Free Text. Questionnaire responses to identifying advantages and disadvantages of BST were examined for common themes. In many cases, multiple themes were identified within responses. Approximately two thirds (68.5\%) of respondents noted advantages of BST. The most common benefits cited were the opportunity to receive feedback from tutors and the opportunity to practice examination technique and clinical skills. These advantages were each noted by approximately one quarter of students (see Table 3). Disadvantages were noted by 313 students with the most common disadvantage cited being excessive class size. Other common disadvantages included time constraints and the unavailability or unwillingness of patients, and they are listed in Table 4.

Respondents were given the opportunity to make additional comments on BST. A large number of respondents described BST as a valuable and enjoyable learning activity. Responses included "bedside teaching is crucial for us to learn the appropriate skills and clinical competence. It's also usually one of the best sessions in the week!" and "I learnt most of my internal medicine and paediatric knowledge from bedside tutorials and they are my strongest knowledge bases-for me this is the best way to learn." Further, the desire for more teaching and its notable absence were frequently expressed, for example, "I currently believe that good bedside teaching is lacking in the course I have been offered" and "I wish we had more bedside teaching, it's very practical and a good way to learn."

\section{Discussion}

The present study is the first multicentre study of BST and the largest study of student opinions of BST available. The data suggested an ideal template for BST comprising 3-4 hours per week, in a class size of 3-4 students, using a format that would involve all students.

BST accounted for $75 \%$ of all teaching in the 1960 s and $16 \%$ in 1978 [1]; however more recent estimates quote prevalence between $8 \%$ and 19\% [3]. The relevance of BST may be
TABLE 3: Advantages of BST.

\begin{tabular}{lc}
\hline Advantages of BST & $\begin{array}{c}\text { Number of respondents } \\
\text { noting this advantage }\end{array}$ \\
\hline $\begin{array}{l}\text { Receiving feedback from tutors } \\
\text { Opportunity to practice examination }\end{array}$ & 132 \\
technique/clinical skills & 130 \\
$\begin{array}{l}\text { Opportunity for tutors to } \\
\text { identify/demonstrate physical signs }\end{array}$ & 104 \\
$\begin{array}{l}\text { Exposure to patients/practical } \\
\text { experience }\end{array}$ & 78 \\
$\begin{array}{l}\text { Developing clinical reasoning skills } \\
\text { Consolidation of material learnt in }\end{array}$ & 66 \\
lectures or in textbooks & 54 \\
Simulation of exam conditions/help \\
towards preparation for assessment \\
Opportunity to ask questions of tutors \\
$\begin{array}{l}\text { Gain tips not available in textbooks } \\
\text { Developing bedside manner }\end{array}$
\end{tabular}

TABLE 4: Disadvantages of BST.

\begin{tabular}{lc}
\hline Disadvantages of BST & $\begin{array}{c}\text { Number of respondents } \\
\text { noting this disadvantage }\end{array}$ \\
\hline Class sizes too large & 57 \\
Time consuming for tutors & 54 \\
Patients unwilling/unavailable & 52 \\
Patient inconvenience & 44 \\
Student & 41 \\
humiliation/intimidation/pressure & 36 \\
Unequal participation within groups & 35 \\
Variable quality of teaching & 32 \\
Difficult to organise &
\end{tabular}

declining due to an increased reliance on medical imaging, biochemical testing [1-3], and subspecialists, [2] leading to a shift in favour of classroom based learning $[5,6]$. This is an international phenomenon, with similar descriptions appearing in studies from Sudan, Saudi Arabia, the United States of America, Iran, Japan, and South Africa [7-14].

In the free text section regarding approach to BST, a common theme raised was the perceived need for consistency of teaching; for example, one student noted that "Having a scheduled time to do bedside teaching would be optimal." The mode response for the optimal hours of BST was three hours per week, with a mean of 4.11 hours per week. It is clear from the data that students still place great value on this particular teaching modality. Psychiatry was seen as the discipline where BST is least useful, and even so, a majority (62.5\%) of respondents felt that psychiatric BST is very or extremely important. The corresponding figure for other disciplines ranged between $74.1 \%$ and $90.4 \%$. BST is a unique situation in which clinical skills and examination technique can be formally supervised and critiqued. Clinical signs are demonstrated, particularly those impossible to learn by textbook such as tactile (e.g., abdominal masses) and aural signs (e.g., heart murmurs). 
Learning at the bedside also improves professional manners, communication skills, and questioning approaches during history taking [3, 15-17]. Furthermore, BST improves clinical reasoning and synthesis, a skill which is rarely taught elsewhere [15]. In a cross-sectional questionnaire study undertaken in Australia in 1997, it was found that $100 \%$ of respondents $(n=136)$ reported BST to be the most effective way of learning clinical skills [16]. The corresponding figure in an American study was 90\% $(n=33)$ [3], although both of these were single institution studies. In addition to improving clinical skills, BST also provides valuable preparation for clinical exams, such as those held by the vast majority of Australian medical schools in final undergraduate examinations [17] and those required for admittance to colleges of fellowship. BST is also the best opportunity for clinical teachers to teach humanistic aspects of medical care such as empathy, respect, and compassion through role modelling at the bedside [18]. It is important to appreciate; however, that bedside teaching alone is unlikely to be sufficient for education of medical students. It is a vital component of a multidimensional, balanced medical curriculum.

The questionnaire also identified a number of barriers to successful and regular BST. A class size of three is most commonly desired by students. Overcrowded tutorials limit the participation of each student and may also increase the discomfort of both student and patient. Due to the increased throughput of hospitals, tutors are often busier with other clinical commitments, meaning diminished opportunities for BST and hence larger class sizes to accommodate all students. A feeling of "performance pressure" has also been described in the literature, where tutors feel unable to provide an adequate quality of BST due to deskilling $[2,6]$. A suggestion highlighted in the study was the importance of ensuring participation of all group members, for example, "The best approach is to involve the whole group and not just subject one individual student to open criticism in front of the patient."

Patients play a large role in successful BST. They may become unwilling to participate because of pain, anxiety, embarrassment, or "student fatigue," where they are often the subject of multiple clinical examinations if they possess a rare or significant sign. Further, they may be unavailable due to procedures, consults, or imaging. While some clinicians have the misconception that BST may upset patents, the literature, however, shows that patients often enjoy being the subject of BST [19] primarily due to an improved understanding of their illness [20], and the majority welcome medical students [21].

The questionnaire data provided a number of suggestions for optimising future BST. A class size of 3-4 students, meeting for 3-4 hours per week, in a format that allowed all students in the group to elicit the key sign would be ideal to a large number of students surveyed.

Limitations to our survey do exist. As the survey was selfadministered, there exists an element of self-selection. The results are specific only to Australia and cannot be applied to other countries. Despite these limitations, this is the first study of its kind in the published literature, and it provides an interesting cross-sectional view of the perceptions towards bedside teaching in Australia.
In conclusion, despite its dwindling prevalence, BST is highly valued by students for the unique benefits it provides. Areas for further research include quantification of bedside teaching and factors affecting it including geographical location, patient population and load, and hospital size and status. Similar prevalence studies may be performed in international settings to compare trends.

\section{Conflict of Interests}

The authors declare that there is no conflict of interests regarding the publication of this paper.

\section{Acknowledgments}

The authors wish to thank the University of New South Wales Medical Society for providing funding to cover the costs of website production and maintenance. Additionally, Michael Stuart is thanked for his assistance with the literature search and preparation and distribution of the questionnaire.

\section{References}

[1] C. P. Gale and R. P. Gale, "Is bedside teaching in cardiology necessary for the undergraduate education of medical students?" Medical Education, vol. 40, no. 1, pp. 11-13, 2006.

[2] M. D. Wenrich, M. B. Jackson, K. S. Ajam, I. H. Wolfhagen, P. G. Ramsey, and A. J. Scherpbier, "Teachers as learners: the effect of bedside teaching on the clinical skills of clinician-teachers," Academic Medicine, vol. 86, no. 7, pp. 846-852, 2011.

[3] K. N. Williams, S. Ramani, B. Fraser, and J. D. Orlander, "Improving bedside teaching: findings from a focus group study of learners," Academic Medicine, vol. 83, no. 3, pp. 257-264, 2008.

[4] Medical Deans Australia and New Zealand, Medical Student Statistics 2012, http://www.medicaldeans.org.au/wp-content/ uploads/Table-1-Website-Stats-2012.pdf.

[5] T. Raupach, S. Anders, T. Pukrop, G. Hasenfuss, and S. Harendza, "Effects of "minimally invasive curricular surgery"a pilot intervention study to improve the quality of bedside teaching in medical education," Medical Teacher, vol. 31, no. 9, pp. e425-e430, 2009.

[6] S. Ramani, J. D. Orlander, L. Strunin, and T. W. Barber, "Whither bedside teaching? A focus-group study of clinical teachers," Academic Medicine, vol. 78, no. 4, pp. 384-390, 2003.

[7] A. M. Ahmed, "Bedside teaching at the cinderella status: options for promotion," Saudi Medical Journal, vol. 31, no. 7, pp. 739-746, 2010.

[8] M. D. Al-Mendalawi, "Medical student and patient perspectives on bedside teaching," Saudi Medical Journal, vol. 31, no. 11, p. $1283,2010$.

[9] C. M. Crumlish, M. A. Yialamas, and G. T. McMahon, "Quantification of bedside teaching by an academic hospitalist group," Journal of Hospital Medicine, vol. 4, no. 5, pp. 304-307, 2009.

[10] N. Kianmehr, M. Mofidi, R. Yazdanpanah, and M. A. Ahmadi, "Medical student and patient perspectives on bedside teaching," Saudi Medical Journal, vol. 31, no. 5, pp. 565-568, 2010.

[11] M. E. K. Ahmed, "What is happening to bedside clinical teaching?” Medical Education, vol. 36, no. 12, pp. 1185-1188, 2002 . 
[12] R. H. Rao, "Perspectives in medical education: 1. Reflections on the state of medical education in Japan," Keio Journal of Medicine, vol. 55, no. 2, pp. 41-51, 2006.

[13] L. Wen, H. Gould, J. T. Nagurney, and L. Wallis, "Perceptions of graduates from Africa's first emergency medicine training program at the University of Cape Town/Stellenbosch University," Canadian Journal of Emergency Medical Care, vol. 14, no. 2, pp. 97-105, 2012.

[14] S. W. Yusuf, "Bedside teaching of medical students," American Journal of Medicine, vol. 118, no. 11, pp. 1304-1305, 2005.

[15] S. Mookherjee and C. L. Chou, "Bedside teaching of clinical reasoning and evidence-based physical examination," Medical Education, vol. 45, no. 5, pp. 508-535, 2011.

[16] B. R. Nair, J. L. Coughlan, and M. J. Hensley, "Student and patient perspectives on bedside teaching," Medical Education, vol. 31, no. 5, pp. 341-346, 1997.

[17] A. Ingham, "The great wall of medical school," Australian Medical Student Journal, vol. 2, no. 2, pp. 5-8, 2011.

[18] P. F. Weissmann, W. T. Branch, C. F. Gracey, P. Haidet, and R. M. Frankel, "Role modeling humanistic behavior: learning bedside manner from the experts," Academic Medicine, vol. 81, no. 7, pp. 661-667, 2006.

[19] Z. Qureshi and S. Maxwell, "Has bedside teaching had its day?" Advances in Health Sciences Education, vol. 17, no. 2, pp. 301-304, 2012.

[20] A. Z. Aldeen and M. A. Gisondi, "Bedside teaching in the emergency department," Academic Emergency Medicine, vol. 13, no. 8, pp. 860-866, 2006.

[21] Y. Marwan, M. Al-Saddique, A. Hassan, J. Karim, and M. AlSaleh, "Are medical students accepted by patients in teaching hospitals?" Medical Education Online, vol. 17, Article ID 17172, 2012. 

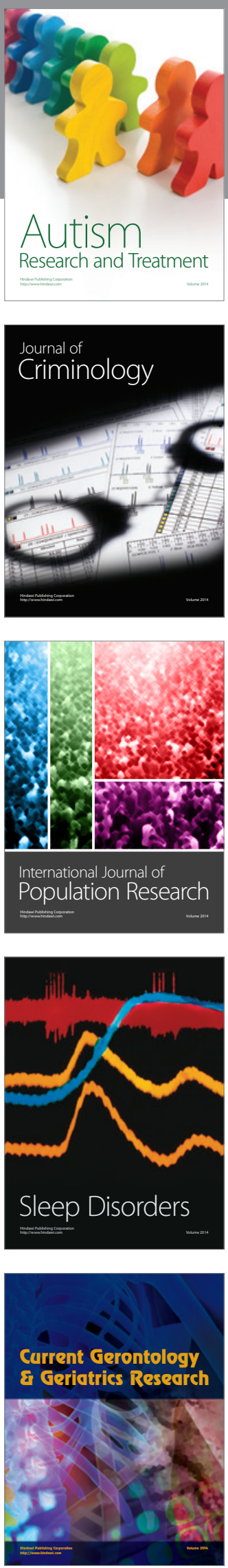
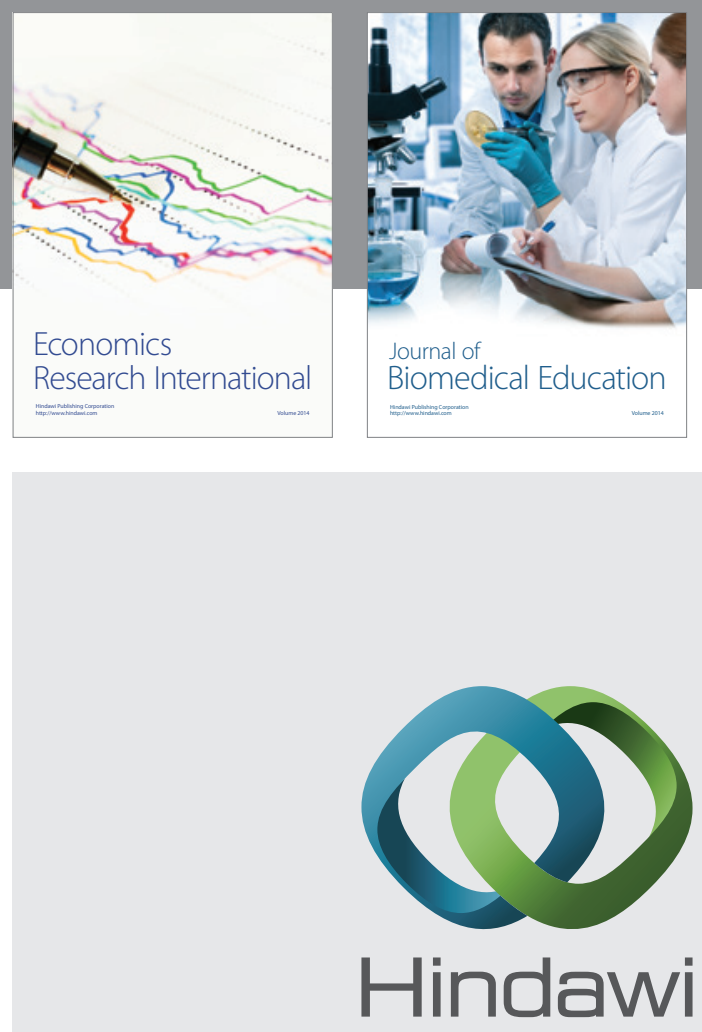

Submit your manuscripts at

http://www.hindawi.com
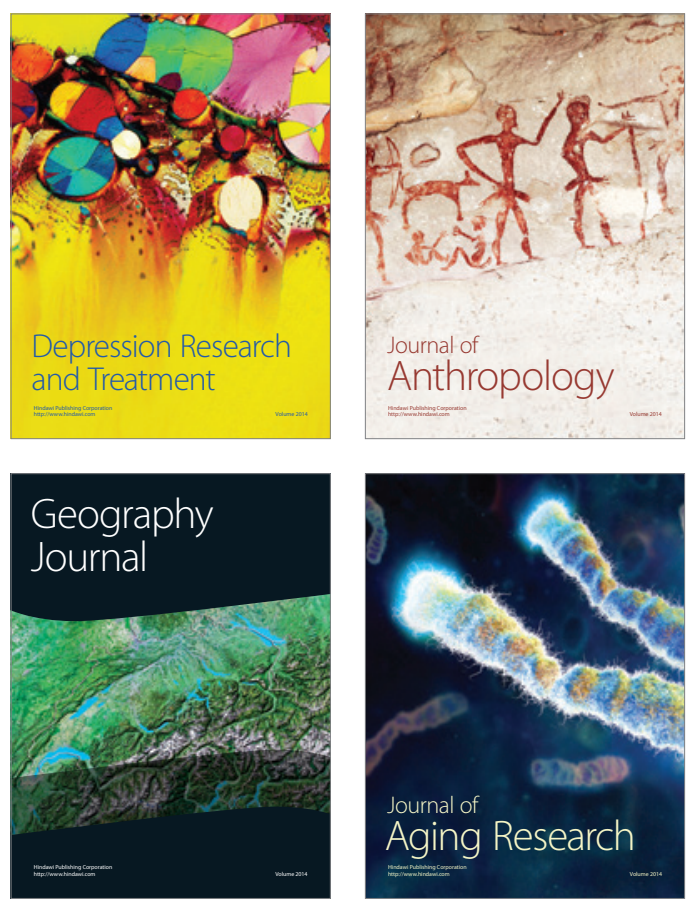
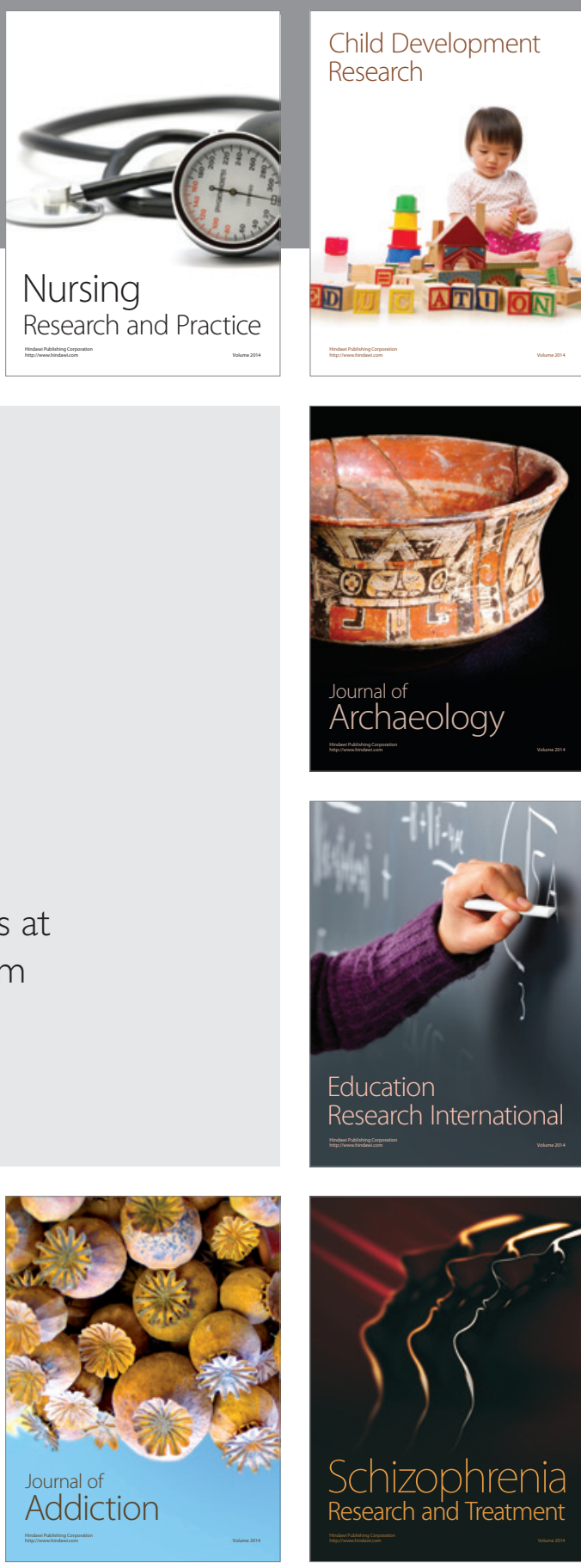

(D)
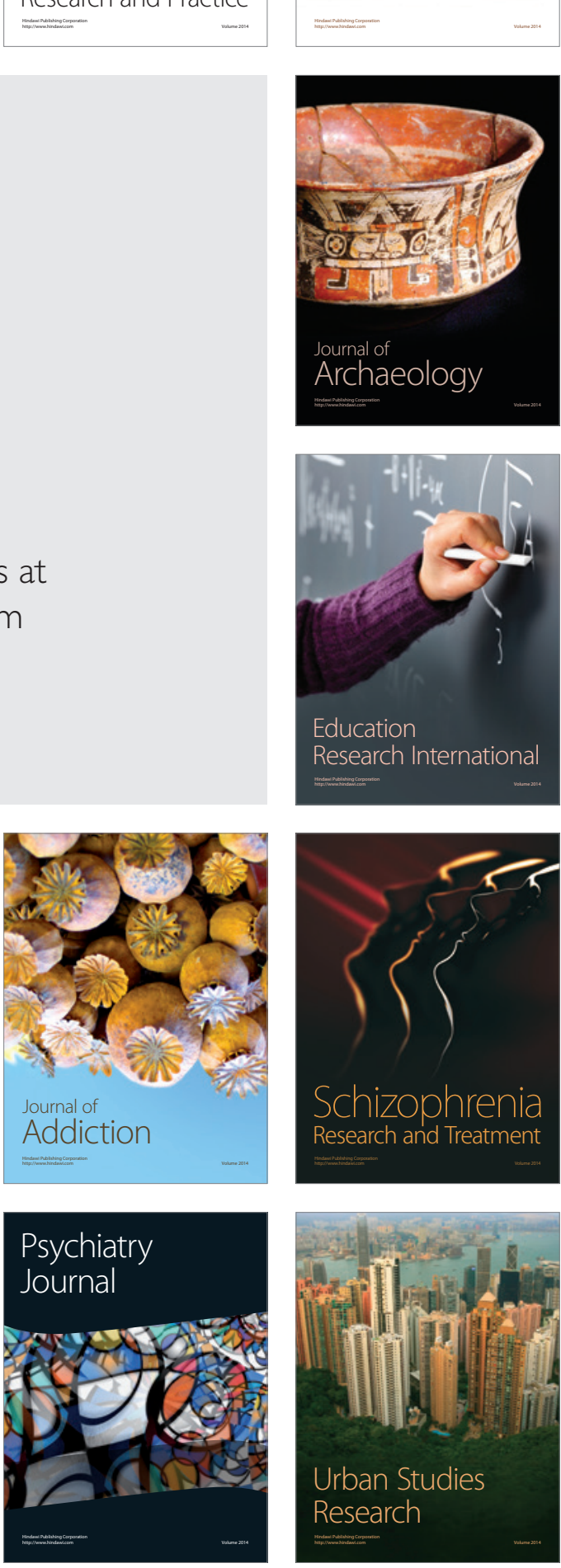